\title{
As mulheres e a enologia no sul do país: a história do Colégio de Viticultura e Enologia na cidade de Bento Gonçalves-RS, Brasil (1959-2019)
}

Women and enology in the south of the country: the history of the College of Viticulture and Enology in the city of Bento Gonçalves-RS, Brazil (1959-2019)

Las mujeres y la enología en el sur del país: la historia del Colegio de Viticultura y Enología en la ciudad de Bento Gonçalves-RS, Brasil (1959-2019)

\section{Edson Carpes Camargo}

\author{
Instituto Federal de Educação, Ciência e Tecnologia do Rio Grande do Sul (Brasil) \\ https://orcid.org/0000-0002-1274-3448 \\ http://lattes.cnpq.br/4271557203774923 \\ edson.camargo@,feliz.ifrs.edu.br
}

Edla Eggert

Pontifícia Universidade Católica do Rio Grande do Sul (Brasil)

http://orcid.org/0000-0002-1980-7053

http://lattes.cnpq.br/8360909218928418

edla.eggert@pucrs.br

\section{Resumo}

Esse texto volta-se para uma narrativa da história do Colégio de Viticultura e Enologia, criado em 1959 na cidade de Bento Gonçalves, no Rio Grande do Sul e que hoje integra o Instituto Federal de Educação, Ciência e Tecnologia do Rio Grande do Sul. Nosso objetivo é apresentar a história da instituição escolar pontuando recortes da história de vida de Adelina Maioli, a primeira mulher a figurar entre o corpo discente do curso Técnico em Enologia. $\mathrm{O}$ processo metodológico perpassou a análise documental, bem como a realização de entrevista semiestruturada. Ao admitir o ingresso da primeira estudante em 1959, a instituição despertou a curiosidade sobre outras mulheres para estudarem nessa escola técnica, abrindo caminhos e possibilitando que o olhar de quem pesquisa se tornasse menos rígido sobre as janelas da história que se abrem para as relações de gênero.

Palavras-chave: Colégio de Viticultura e Enologia. Relações de Gênero. Ensino Técnico. 


\begin{abstract}
This text refers to a narrative history of the College of Viticulture and Enology, created in 1959 in the city of Bento Gonçalves, Rio Grande do Sul, which nowadays integrates the Federal Institute of Education, Science and Technology of Rio Grande do Sul. Our goal is to present the history of the school institution showing parts of Adelina Maioli life story, the first woman to be among the student body of the Technical course in Enology. The methodological process had the document analysis, as well as conducting a semi-structured interview. Allowing the admission of the first female student in 1959, the institution aroused curiosity about other women to study in this technical school, opening paths and allowing the researches' view to become less rigid about the story windows that open to gender relations.
\end{abstract}

Keywords: College of Viticulture and Enology. Gender Relations. Technical education.

\title{
Resumen
}

Este texto mira hacia una narrativa de la historia de la Escuela de Viticultura y Enología, creada en 1959 en la ciudad de Bento Gonçalves, en el Rio Grande do Sul y que actualmente forma parte del Instituto Federal de Educación, Ciencia y Tecnología del Rio Grande do Sul. Nuestro objetivo es presentar la historia de la institución escolar, desde el punto de vista de la historia de vida de Adelina Maioli, la primera mujer que ha estado entre el cuerpo discente del curso Técnico Profesional en Enología. La metodología se ha dado a través del análisis documental, además de la realización de una entrevista semiestructurada. Cuando se permitió el acceso de la primera mujer estudiante en 1959, la institución despertó la curiosidad sobre otras mujeres para estudiar en esa escuela técnica profesional, abriendo caminos y posibilitando que la mirada del que investiga se volviera menos rígida sobre las ventanas de la historia que se abren hacia las relaciones de género.

Palabras claves: Colegio de Viticultura y Enología. Relaciones de género. Educación técnica. 


\section{Introdução}

Colocamo-nos diante de uma artesanial, assim como os estudos de Silva (2000) e Luporini (2005), de utilizar o registro fotográfico como fonte de pesquisa para a [re]constituição da memória coletiva ${ }^{2}$ desta Instituição de Ensino, marcada pelo contexto histórico-cultural que se desencadeia a partir de 1949, quando são criadas as Escolas Industriais e Técnicas, oferecendo a formação profissional em nível equivalente ao do secundário, dando início, formalmente, conforme menciona Machado (1982), ao processo de vinculação do ensino industrial à estrutura do ensino do país ${ }^{3}$.

Entre os anos de 1956 e 1961 a prioridade na área da educação foi a formação de profissionais orientados para as metas de desenvolvimento do país ${ }^{4}$. É neste espaço temporal que, em 22 de outubro de 1959, através da Lei Ordinário 3.646/59, foi criada a Escola de Viticultura e Enologia de Bento Gonçalves ${ }^{5}$, atualmente um dos campi do Instituto Federal de Educação, Ciência e Tecnologia do Rio Grande do Sul e que estava subordinada ao Instituto de Fermentação do Serviço Nacional de Pesquisas Agronômicas do Centro Nacional de Ensino e Pesquisas Agronômicas.

Assim como Silva et al (2009), realizaremos uma tentativa de não enfatizar apenas "a quantificação ou descrição dos dados recolhidos, mas a importância das informações que podem ser geradas a partir de um olhar cuidadoso e crítico das fontes documentais" (p. 4556), contribuindo para compreendermos o passado e pensarmos o futuro.

\section{O surgimento da Escola de Viticultura e Enologia}

O interesse pela criação de uma escola de viticultura e enologia na região da Serra Gaúcha pairava sobre o município de Bento Gonçalves durante o período de 1950, conforme demonstra Jalfim (1993) em seu estudo intitulado "Elementos para o estudo da agroindústria vinícola: uma abordagem da Cooperativa Vinícola Aurora" no qual, partindo de entrevistas com sócios-fundadores e análise de documentos pertencentes a vinícolas da localidade, a pesquisadora identifica o crescimento da produção vinícola na região a partir de 1936. Entretanto, "as precárias condições de transporte e de acondicionamento ocasionavam a fermentação da uva, comprometendo, inevitavelmente, a qualidade do vinho a que daria

\footnotetext{
${ }^{1}$ Processos pelos quais o artesão transita, em que se fazem presentes a experimentação e a investigação em busca de um resultado adequado. A artesania torna-se, então, não somente o produto final, mas o ato de fazer o artesanato, o processo de produção. Esse artigo é fruto da artesania da Tese de doutorado defendida no Programa de Pós-Graduação em Educação da Universidade do Vale do Rio dos Sinos, com financiamento do Instituto Federal de Educação, Ciência e Tecnologia do Rio Grande do Sul.

${ }^{2}$ Utilizaremos o conceito de "memória coletiva" proposto por Maurice Halbwachs (2006) no momento em que analisa o caráter social da memória a partir de um percurso sociológico sistemático, assegurando que "nossas lembranças permanecem coletivas, e elas nos são lembradas pelos outros, mesmo que se trate de acontecimentos nos quais só nós estivemos envolvidos" (p. 30). Nesse sentido, contrapondo-se à ideia de que a memória é um fenômeno individual ou biológico, o autor afirma que as lembranças são constituídas a partir da memória coletiva, a qual está na base da memória individual.

${ }^{3}$ Conforme Machado (1982), somente a partir de 1949 os alunos formados nos cursos técnicos ficavam autorizados a ingressar no ensino superior em área equivalente à da sua formação.

${ }^{4}$ No período entre 1956 e 1960 o Presidente Juscelino Kubitschek lança o denominado Plano de Metas, no qual concedia "ampla liberdade ao capital estrangeiro" (MACHADO, 1982, p. 51), resultando na modernização do mercado comercial e na necessidade de formação técnica para atender à sua expansão. Denominado de 50 anos em 5, o Plano de Metas de Juscelino Kubitschek estava subdividido nos setores: energia, transporte, alimentação, indústria de base e educação.

${ }^{5}$ A criação da Escola de Viticultura e Enologia ancora-se no Decreto-Lei no 9.613, de 20 de agosto de 1946, que estabelece as bases de organização e de regime do ensino agrícola, destinado essencialmente à preparação profissional dos trabalhadores da agricultura.
} 
origem" (p. 691). Sendo assim, ter uma escola que colocasse o produtor rural em contato com as novas tendências de produção, transporte e vinificação tornava-se o objetivo principal das empresas vinícolas, pois assim teriam um produto de melhor qualidade e em maior quantidade, não interferindo, portanto, no valor pago ao agricultor ${ }^{6}$.

Conforme o estudo realizado por Anderle (1998), a intenção de criar uma instituição que tivesse como foco o ensino da Viticultura e da Enologia já havia sido manifestada pelo então diretor do Laboratório Central de Enologia do Instituto de Fermentação do Ministério da Agricultura, professor Manuel Mendes da Fonseca, em 1937, momento em que acontecia o $3^{\circ}$ Congresso Brasileiro de Viticultura e Enologia no Rio de Janeiro ${ }^{7}$. Sabendo disso, em 1944, o então prefeito municipal de Bento Gonçalves, João Mário de Almeida Dentice, assina o Decreto-Lei $\mathrm{n}^{\circ}$ 71, autorizando a aquisição de um grupo de imóveis e transferindo ao Governo Federal a área de $341.560 \mathrm{~m}^{2}$ destinados à construção de uma estação de Enologia pelo Ministério da Agricultura.

A elaboração do projeto que resultou na construção da Escola de Viticultura e Enologia, conforme Cardoso (2012), foi conduzida pelo vice-prefeito de Bento Gonçalves do período de 1950, Loreno Augusto Garcia, juntamente com Childerico Bevilaqua ${ }^{8}$ e, em fevereiro de 1960, com a nomeação de Amyntas de Assis Lage para diretor, entra em funcionamento a Escola de Viticultura e Enologia, estabelecida provisoriamente no prédio da Estação Experimental de Enologia, transformada posteriormente em Empresa Brasileira de Pesquisa Agropecuária (EMBRAPA). Levando em consideração que a escola recém estava sendo criada e o curso ofertado era desconhecido da população, mesmo assim quinze alunos matricularam-se na primeira turma 9 .

A década de 1960 serviu de cenário para muitas mudanças que afetaram diretamente o funcionamento da Instituição lócus deste estudo. Com o Decreto $\mathrm{n}^{\mathrm{o}} 53.558$, de 13 de fevereiro de 1964, a Escola de Viticultura e Enologia passa a ser denominada de Colégio de Viticultura e Enologia (BRASIL, 1964), assumindo a sigla C.V.E., a qual se tornará, anos depois, a marca dos produtos fabricados e comercializados pela Instituição. Desde sua fundação, o C.V.E. esteve vinculado ao Ministério da Agricultura. Contudo, em 1967, seguindo o que preconizava o artigo $6^{\circ}$ da Lei de Diretrizes e Bases da Educação Nacional no 4.024, de 20 de dezembro de 1961, é publicado o Decreto $\mathrm{n}^{\circ}$ 60.731, transferindo a responsabilidade pelos colégios agrícolas e pelas universidades rurais para o Ministério da Educação e Cultura, sendo criada nesse Ministério a Diretoria do Ensino Agrícola (BRASIL, 1967).

Neste período de transição entre um Ministério e outro, Anderle (1998) menciona que a Instituição enfrentou inúmeras dificuldades, que se prolongaram por vários anos, com a falta de professores habilitados, pessoal de apoio, recursos para alimentação e manutenção dos alunos, ao mesmo tempo em que eram inaugurados o alojamento masculino e outros ambientes de convivência. Na tentativa de alterar esta situação de dependência financeira foi

\footnotetext{
${ }^{6}$ Até o ano de 2014, o debate sobre o valor pago ao produtor é acirrado, uma vez que há uma produção muito grande de uva na região, gerando uma oferta além das expectativas de demanda.

${ }^{7}$ Os dados apresentados fazem parte de documentos avulsos pertencentes ao acervo do setor de Comunicação do IFRS - campus Bento Gonçalves.

${ }^{8}$ Childerico Bevilaqua foi diretor do Instituto de Fermentação, encarregado da fiscalização do vinho e das estações experimentais de Enologia durante as décadas de 1950 e 1960.

${ }^{9}$ Não foram encontrados documentos que mencionassem quantas vagas foram abertas para a primeira turma, nem para as subsequentes. Contudo, o Decreto $n^{\circ} 538$, de 23 de janeiro de 1962, que aprova o Regulamento da Escola de Viticultura e Enologia de Bento Gonçalves e dá outras providências, no Capítulo III, Seção I, Art. 15, menciona que "o número de matrículas será fixado anualmente pelo Comitê Técnico Consultivo da Escola atendida a capacidade do estabelecimento". Considerando ainda o estudo realizado por Souza (2005) denominado Mudanças promovidas no setor vinícola do Rio Grande do Sul pela inserção de profissionais especializados nas áreas de viticultura e enologia, no qual são elencados o número de formandos do curso Técnico em Viticultura e Enologia desde 1962, acreditamos que quinze alunos matriculados na primeira turma tenha sido uma procura satisfatória.
} 
implantado o Sistema Escola-Fazenda, o qual a Instituição já adotava em sua filosofia.

O "aprender fazendo" não era uma novidade nos Colégios Agrícolas. De acordo com Tavares (2007), o Sistema Escola-Fazenda visava integrar ensino, trabalho e produção, lançando mão de modelos estruturais que seriam aplicados mais tarde em todas as escolas agrotécnicas da rede federal. Visando dar conta desta nova realidade e cumprindo com as exigências do programa de financiamento internacional para a implantação de projetos agropecuários em escolas técnicas, é criada a Coordenação Nacional do Ensino Agropecuário $(\mathrm{COAGRI})^{10}$, que implementa o Sistema Escola-Fazenda, tendo por princípio "aprender a fazer e fazer para aprender", intencionando possibilitar ao estudante a auto-sustentação, incorporando a educação pelo trabalho às práticas pedagógicas desenvolvidas nas instituições, reforçando um caráter tecnicista de educação. Com isso, o Centro Nacional de Aperfeiçoamento de Pessoal para a Formação Profissional (CENAFOR) elaborou um Manual da Escola-Fazenda ${ }^{11}$, ressaltando o vínculo entre ensino e trabalho, visando estimular os alunos a "produzir". Segundo Marques (2005), os alunos realizavam todas as tarefas começando pela plantação e finalizando com a comercialização, momento em que participavam também da partilha resultante das vendas.

Neste cenário, os principais objetivos do Sistema Escola-Fazenda conforme documento do Ministério da Educação (1977) eram

a. Proporcionar melhor formação profissional aos educandos, dando-lhes vivência com os problemas reais dos trabalhos agropecuários;

b. Despertar o interesse pela agropecuária;

c. Levar os estudantes a se convencerem de que agropecuária é uma indústria de produção;

d. Oferecer aos estudantes oportunidades de iniciarem e se estabelecerem, progressivamente, num negócio agropecuário;

e. Ampliar o raio de ação educativa do estabelecimento, proporcionando aos agricultores circunvizinhos e aos jovens rurícolas conhecimento das práticas agropecuárias recomendáveis;

f. Despertar no educando o espírito de cooperação e auxílio mútuo. (s/n).

O Manual do Sistema Escola-Fazenda destacava também os componentes estruturais de uma Escola-Fazenda, dentre os quais estão as salas de aula; o Laboratório de Prática e Produção, substituído posteriormente pelas Unidades Educativas de Produção (UEPS); o Programa Agrícola Orientado, excluído do sistema pouco tempo depois; e a Cooperativa Escolar. Vale ressaltar que esta estrutura ainda persiste em muitos campi dos atuais Institutos Federais oriundos de escolas agrotécnicas, inclusive no que é apresentado neste estudo, ou por desconhecerem as diretrizes que originam os Institutos Federais ou por estarem imersos na metodologia da Escola-Fazenda por um período muito longo, como demonstram os estudos de Koller (2003) e Figueiredo (2008). A figura 1 apresenta os elementos que compunham a estrutura da Escola-Fazenda e a sua relação de dependência:

\footnotetext{
${ }^{10}$ O Decreto n ${ }^{\mathrm{o}} 72.434$, de 9 de julho de 1973, cria a COAGRI com vinculação à Secretaria de Ensino de $1^{\circ} \mathrm{e}$ $2^{\circ}$ Graus do Ministério da Educação e Cultura (BRASIL, 1973), provocando mudanças no ensino agrícola com maior autonomia financeira das instituições e a comercialização de produtos agrícolas oriundos de projetos desenvolvidos a partir do Sistema Escola-Fazenda.

${ }^{11}$ Tavares (2007) menciona que em 1972, Alberto Campos Silva, António Salvador Espósito, Carlos Felício Vanni, Henrique da Silva Cabral, Jairo Tavares de Oliveira, José Leocyr Dornelles Mimussi, Júlio Marcos Araújo, Léo Ardenghi, Luiz Fernando Costa A. Campis, Luiz de Oliveira e Silva Sobrinho, Paulo Barreto Campeio, Pedro Jaime Genu, Shigeo Mizoguchi e Wolga Peçanha, convidados pelo CENAFOR elaboram o Manual Escola-Fazenda, contendo os objetivos para o Sistema Escola-Fazenda.
} 
Figura 1: Representação da estrutura de uma Escola-Fazenda

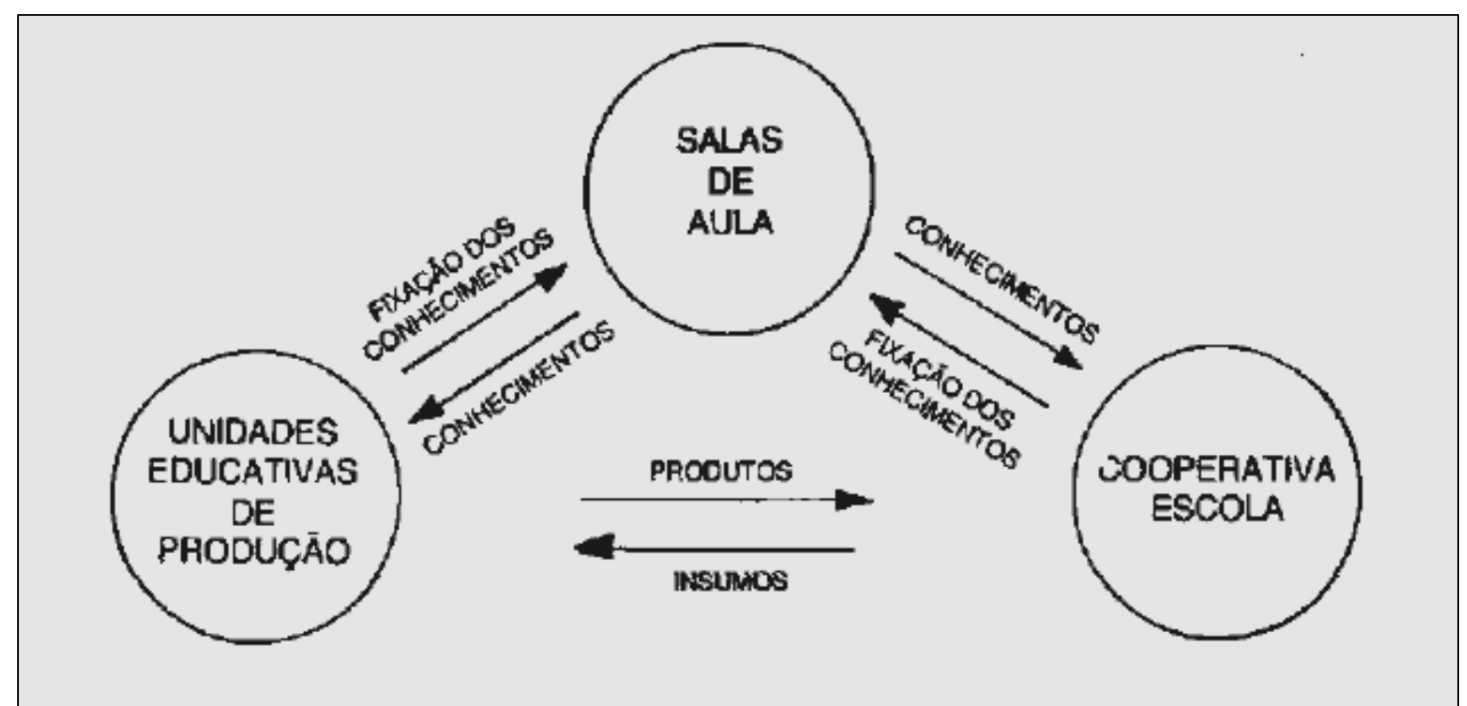

Fonte: BRASIL. Diretrizes de Funcionamento de Escolas Agrotécnicas. Brasília: MEC/SENETE, 1990, p. 11.

Estes componentes estruturais foram dimensionados pela Secretaria Nacional de Educação Tecnológica (SENETE) por meio da publicação das Diretrizes de Funcionamento de Escolas Agrotécnicas (1990). A SENETE apresentava cada um dos componentes explicitando a sua função para o desenvolvimento do sistema. Nesse sentido, a sala de aula era considerada o local em que a capacidade de análise e reflexão eram estimuladas em prol da formação do educando; as unidades educativas de produção ${ }^{12}$ eram as responsáveis pelo processo produtivo, funcionando como laboratórios de ensino e a cooperativa-escola constituída por alunos com estrutura e estatuto próprios visava a autoformação (BRASIL, 1990).

É neste cenário que o Colégio de Viticultura e Enologia (CVE) passa a integrar a rede de escolas da COAGRI, tentando minimizar as suas dificuldades financeiras e buscando apoio governamental com a implantação, em 1975, do curso Técnico em Agricultura. Diante desta perspectiva, a produção de vinhos, que até o momento era artesanal e servia como atividade prática para complementar o ensino, passa a ser comercial, gerando recursos financeiros que auxiliavam a instituição na sua manutenção. Além desse, outros projetos desenvolvidos nas UEPs eram posteriormente comercializados na cooperativa-escola. Deste processo de comercialização surge a marca C.V.E., que estampa os rótulos de vinhos, sucos e espumantes produzidos e comercializados pela cooperativa-escola.

A estruturação do Sistema Escola-Fazenda tem continuidade com a criação da Cooperativa Escolar e de Trabalho dos Alunos do Colégio de Viticultura e Enologia ${ }^{13}$. Apesar de já manterem atividades associativistas antes deste período, é somente neste momento que os/as estudantes se organizam de forma cooperativa e são certificados pelo Instituto Nacional de Colonização e Reforma Agrária (INCRA) sob o $n^{\circ}$ 2791/79. O estatuto da cooperativa é apresentado e aprovado na primeira reunião da entidade. Cabe ressaltar, entretanto, que não

\footnotetext{
${ }^{12}$ Cada UEP inclui uma sala-ambiente nas quais são ministradas as disciplinas de Agricultura e de Zootecnia, constituindo uma unidade didática completa. As Diretrizes de funcionamento das escolas agrotécnicas estabelece como parâmetro a existência de oito UEPs em cada escola, estando assim distribuídas: 3 unidades de Agricultura Olericultura e jardinagem, Culturas regionais e temporais e Cultura perenes; 3 unidades de Zootecnia - Animais de pequeno porte, Animais de médio porte e Animais de grande porte; 1 unidade de Mecanização Agrícola e 1 unidade de Agroindústria (BRASIL, 1990).

13 A cooperativa escolar é fundada em 22 de abril de 1979, conforme consta no livro de Atas desta organização (COOPERATIVA, 1979).
} 
há registro de meninas participando da primeira gestão da cooperativa escolar, e creditamos isso ao fato de que o foco inicial da cooperativa era subsidiar a alimentação e prover condições para a manutenção do internato, o qual era uma exclusividade masculina.

A participação feminina passa a ser um pouco mais efetiva no ano seguinte ${ }^{14}$, momento em que as meninas participam como integrantes de uma das chapas que concorriam à gestão da cooperativa. Contudo, entre os períodos de 1979 e 1994, os cargos pleiteados pelas mulheres nunca foram a presidência da cooperativa ${ }^{15}$. Para ampliar este debate, ao analisar a contribuição da crítica feminista para o conhecimento científico, Lourdes Bandeira (2008) menciona a ausência feminina nas discursividades filosóficas, históricas e científicas, uma vez que a ciência moderna foi construída com base na naturalização dos gêneros, justificando a incapacidade das mulheres participarem das discussões em virtude do seu obscurantismo e de suas emoções.

\section{A transformação de Colégio Agrícola em Instituto Federal}

O período compreendido entre 1970 e 1980 ficou marcado como o momento em que as relações das pessoas com o meio constituíram o elemento essencial para o progresso, ocorre a transição dos colégios agrícolas, que passam do foco voltado ao ensino agrícola para o técnico agrícola, transformando-se em escolas agrotécnicas em todo o país. Fazendo parte deste momento, o Colégio de Viticultura e Enologia torna-se Escola Agrotécnica Federal de Bento Gonçalves (EAFBG) ${ }^{16}$, contemplando o ensino agrícola baseado no Sistema Fazenda-Escola.

A transformação da então Escola Agrotécnica em Centro Federal de Educação Tecnológica (CEFET-BG) foi amplamente debatida pelo Comitê Técnico Consultivo (CTC) da Escola e pela comunidade escolar, vindo a culminar com a sua efetivação em agosto de $2002^{17}$. De acordo com o Decreto 2.406, os CEFETs constituem uma "modalidade de instituições especializadas de educação profissional" (BRASIL, 1997), que tem como características básicas:

I - oferta de educação profissional, levando em conta o avanço do conhecimento tecnológico e a incorporação crescente de novos métodos e processos de produção e distribuição de bens e serviços;

II - atuação prioritária na área tecnológica, nos diversos setores da economia;

III - conjugação, no ensino, da teoria com a prática;

IV - integração efetiva da educação profissional aos diferentes níveis e modalidades de ensino, ao trabalho, à ciência e à tecnologia;

V - utilização compartilhada dos laboratórios e dos recursos humanos pelos diferentes níveis e modalidades de ensino;

\footnotetext{
${ }^{14}$ Conforme consta na ata de $\mathrm{n}^{\mathrm{o}} 6$, de 21 de março de 1980, da Cooperativa-escola.

15 Quanto a esse assunto, temos somente a ata $n^{\circ} 40$, de 20 de março de 1991, a qual menciona que o presidente se retira e a secretária assume a função, sendo mencionada em ata como "a presidenta". Conforme os registros do período de 1979 a 1994, nenhuma outra mulher assumiu a presidência da cooperativa escolar.

${ }^{16}$ O Decreto $\mathrm{n}^{\mathrm{o}}$ 83.925, de 4 de setembro de 1979, orienta em seu artigo $1^{\mathrm{o}}$ que "os estabelecimentos de ensino subordinados à COAGRI, órgão vinculado à Secretaria de Ensino de $1^{\mathrm{o}}$ e $2^{\mathrm{o}}$ Graus do Ministério da Educação e Cultura, terão a denominação uniforme de ESCOLA AGROTÉCNICA FEDERAL, seguida do nome da cidade em que se localiza o estabelecimento" (BRASIL, 1979). Sendo assim, o Colégio de Viticultura e Enologia passa a denominar-se Escola Agrotécnica Federal de Bento Gonçalves até o ano de 1985, quando altera sua nomenclatura para Escola Agrotécnica Federal Juscelino Kubitschek.

${ }^{17}$ De acordo com Decreto Presidencial de 16 de agosto de 2002, é implantado o Centro Federal de Educação Tecnológica de Bento Gonçalves - CEFET/BG. Vale ressaltar que a Lei 8.948/94 já possibilitava a transformação das Escolas Agrotécnicas em Centros Federais de Educação Tecnológica em 1994.
} 
VI - oferta de ensino superior tecnológico diferenciado das demais formas de ensino superior;

VII - oferta de formação especializada, levando em consideração as tendências do setor produtivo e do desenvolvimento tecnológico; VIII - realização de pesquisas aplicadas e prestação de serviços:

IX - desenvolvimento da atividade docente estruturada, integrando os diferentes níveis e modalidades de ensino, observada a qualificação exigida em cada caso;

$\mathrm{X}$ - desenvolvimento do processo educacional que favoreça, de modo permanente, a transformação do conhecimento em bens e serviços, em benefício da sociedade;

XI - estrutura organizacional flexível, racional e adequada às suas peculiaridades e objetivos;

XII - integração das ações educacionais com as expectativas da sociedade e as tendências do setor produtivo (BRASIL, 1997).

Sendo assim, a prioridade dos cursos oferecidos pelos CEFETs centrava-se tanto nos de nível Técnico de Ensino Médio como em Superiores de Tecnologia, suscitando várias críticas, todas elas fundamentadas na ideia de que estes últimos estariam voltados para a formação de trabalhadores em um curto espaço de tempo, o que beneficiaria os setores produtivos em detrimento da qualidade do ensino. Com o foco no ensino aplicado, de acordo com as demandas dos setores produtivos locais, e o aumento de vagas de forma imediata, é criado no CEFET-BG o curso superior de Tecnologia em Viticultura e Enologia, sendo posteriormente implantados os Cursos Superiores de Tecnologia em Alimentos e Tecnologia em Horticultura.

Com a criação dos 38 Institutos Federais é instituída a Rede Federal de Educação Profissional, Científica e Tecnológica através da lei 11.892/2008. Segundo esta lei, os CEFETs, as Escolas Agrotécnicas e as Escolas Técnicas passam a compor os Institutos Federais de Educação, Ciência e Tecnologia, especializados em oferecer educação profissional e tecnológica nas diferentes modalidades de ensino. A criação desses Institutos Federais marcou profundamente a educação brasileira com uma proposta de formação técnica e profissional baseada nos conceitos de ensino integrado e verticalizado ${ }^{18}$. Neste contexto, o CEFET/BG torna-se o campus Bento Gonçalves do Instituto Federal de Educação, Ciência e Tecnologia do Rio Grande do Sul (IFRS).

\section{As mulheres começam a escrever as suas histórias na enologia}

As fotografias da Escola de Viticultura e Enologia nos mostraram que apenas uma mulher havia participado da primeira turma do curso Técnico em Viticultura e Enologia da escola inaugurada em 1959 e, diante disso, sentimos a necessidade de encontrá-la, de indagar sobre como era o ensino naquela época, como era a sua relação com colegas e professores/as e que lembranças a memória guardava. Ou tentava esquecer. Acreditávamos que seria difícil encontrar vestígios que levassem ao encontro da possível pesquisada. Contudo, somos sujeitos de um mundo tecnológico e eis que, ao procurar em uma rede social, encontramos Adelina Mussoi Maioili, conectada ao mundo virtual. Mais interessante ainda foi descobrir que uma das filhas de Adelina atuava na mesma instituição lócus deste estudo, no momento em que o estudo era realizado. A coleta das informações se desenvolveu então a partir de uma entrevista semi-estruturada realizada na residência da entrevistada, com o auxílio de um gravador de áudio e posterior degravação do material.

\footnotetext{
${ }^{18}$ Uma das fortes características dos Institutos Federais diz respeito à verticalização do ensino, concretizada pela oferta de diferentes níveis e modalidades da educação profissional.
} 
Uma das lembranças de Adelina referia-se ao momento em que o Regulamento da Escola foi aprovado e foram concluídas as obras do que seria denominado de Bloco Central, o qual abrigaria salas de aula, a parte administrativa da instituição e alguns parcos laboratórios, situação que fazia com que as atividades práticas continuassem a ser desenvolvidas junto à Estação Experimental de Enologia. Ao questioná-la sobre como eram realizadas as aulas práticas em 1959, ela nos responde que

[...] nós fizemos todos aqueles terraços da enologia. Fomos nós que fizemos todos aqueles naquela baixada, foi lá que nós aprendemos a usar os teodolitos. Aquelas árvores lá da frente também fomos nós que plantamos, porque a gente teve o primeiro e o segundo ano de aula lá embaixo, $[. .$.$] e depois então construíram aqui em cima, só no terceiro$ ano nós viemos aqui para cima. A gente fez tudo, ajardinamento e aprendeu a nivelar o chão pra fazer terraço (MAIOLI, 2013).

Neste momento da entrevista, Adelina pede licença para ir até o quarto e retorna com uma caixa carregada de recordações: eram as fotografias de inúmeras atividades realizadas na Escola de Viticultura e Enologia durante o período em que estudava nesta instituição. Dentre tantas, estava a fotografia que [res]guardava a imagem de toda a turma no momento da conclusão do curso, em 15 de dezembro de $1962^{19}$ (Figura 2).

Figura 2: Primeira turma de formandos da E.V.E., em 1962. De baixo para cima: Waldomiro Vicente Fontanive, Adelina Maria Mussoi, Firmino Splendor e José Pozza. Noeli Gugel, José Cândido Abella Porto, Valdir Camerini, Aurindo Fontanive, Terílio Possamai e João Vignatti. Antônio José Grazzia e Leonir Francisco Baldissera. No alto, Ivo Siviero.

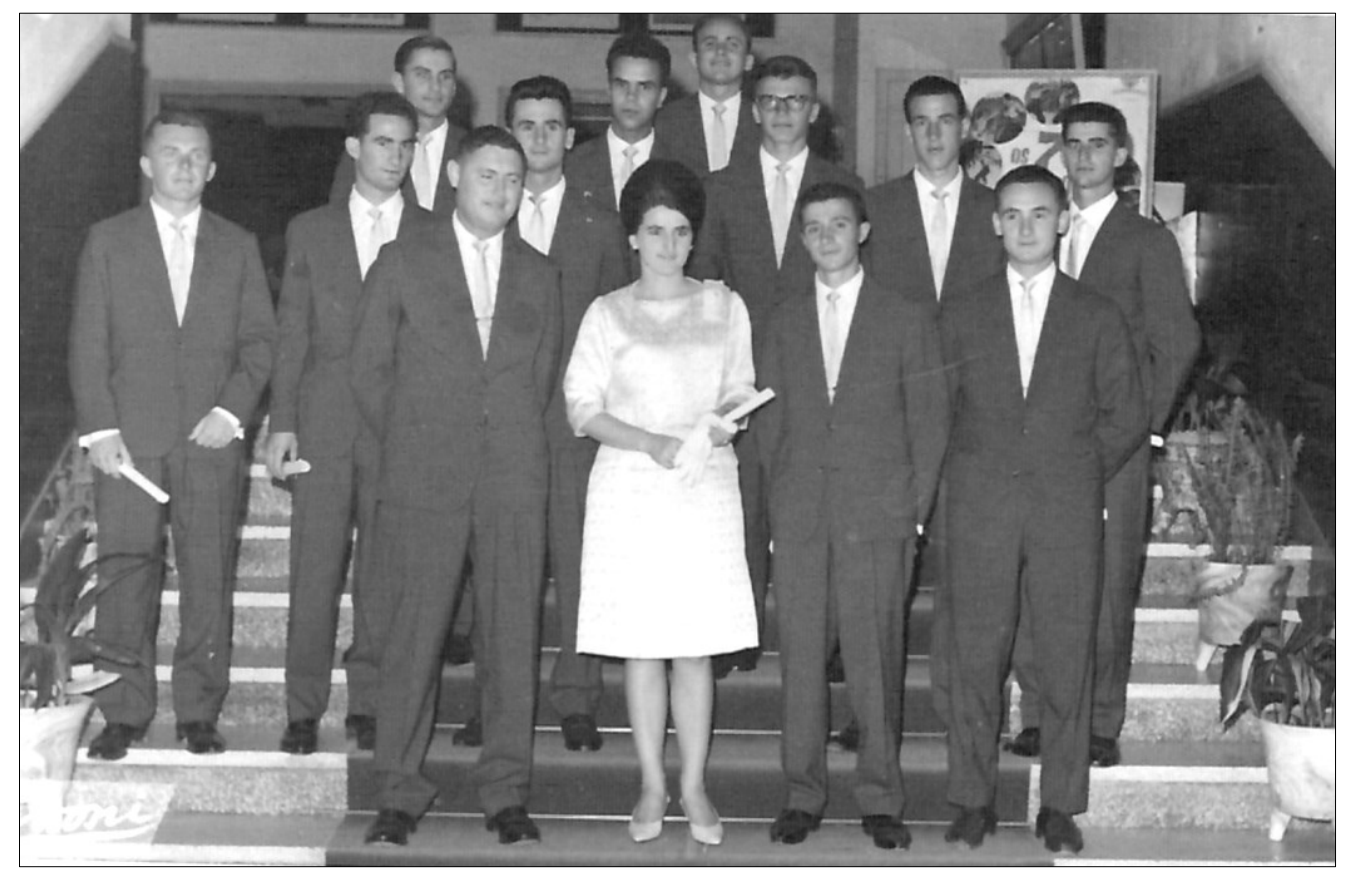

Fonte: Acervo pessoal de Adelina Maria Mussoi Maioli.

${ }^{19}$ De acordo com Anderle (1998) e Cardoso (2012), é com o lema Vis in labore (Na força do trabalho) e tendo como paraninfo o empresário local Carlos Dreher Filho, que cola grau nesta data a primeira turma de Técnicos em Viticultura e Enologia da Escola de Viticultura e Enologia (E.V.E.). 
As fotografias mantinham vivas as memórias das primeiras visitas técnicas, como a que ocorreu na Fábrica Cinzano; os primeiros jogos escolares, em que meninos e meninas estavam envolvidos/as e também os momentos de atividades práticas, em que a poda tornava-se essencial.

Contudo, uma mulher concluir um curso técnico no contexto histórico-cultural de 1962 era perturbador para os preceitos patriarcais que limitavam as mulheres ao ambiente doméstico e a seus afazeres, introduzindo uma segregação sexual na divisão do trabalho. Perrot (2005), ao problematizar o que é considerado um trabalho de mulher no século XIX, menciona que as profissões femininas neste período "inscrevem-se no prolongamento das funções naturais, maternais e doméstica" (p. 252), induzindo-as a especialidades que seriam próprias das mulheres, de acordo com a condição biológica e reforçando a dominação masculina até o século XX.

$\mathrm{Na}$ ambientação da cena expressa na figura 2, os homens usam terno e sapatos de cor escura, bem como fazem uso de gravata. Não é possível precisar qual a cor do vestido e dos sapatos da mulher da fotografia, uma vez que a original é em preto e branco. Contudo, há de se evidenciar o destaque do vestido ao lado dos ternos escuros. Observe-se ainda, que o ambiente tenha sido organizado propositalmente para o evento, contando com um tapete que cobria os degraus e arranjos de flores dispostos nas laterais da escada, o que em muitos eventos serve para ornamentar e também valorizar o momento. Um dos formandos que está na segunda linha planimétrica encontra-se afastado dos demais, ganhando com isso maior visibilidade pela possibilidade de ser visto e reconhecido imediatamente por quem vê a imagem. Apesar da fotografia estar identificada no canto inferior esquerdo por quem a produziu, muitos/as dos/as formandos/as estavam com o olhar desfocado da câmera, prestando atenção em movimentações que aconteciam fora do ambiente cênico da imagem. Quanto à composição perspectiva, o centro da imagem é ocupado pela única figura feminina, restando um dos homens situado na última linha planimétrica desacompanhado e fora do traçado central.

Além de um maior número de alunos do sexo masculino, como é possível observar na figura 2, os escritos de Anderle (1998) mencionam uma conjuntura em que o ensino técnico recém instaurado na Escola de Viticultura e Enologia é ministrado de homens para homens. Observamos isso em dois momentos: a lista de nomes dos primeiros professores, sendo todos homens ${ }^{20}$ e no segundo, na primeira turma de formandos apenas uma mulher, denotando a reduzida participação feminina no ensino técnico, o que se prolonga por mais algumas décadas em Bento Gonçalves. Não é uma característica única deste espaço, já que, durante a década de 1960, as escolas técnicas de todo o país eram consideradas um reduto masculino. O estudo realizado por Figueiredo (2008) exemplifica muito bem essa masculinização do ensino técnico ao analisar o curso técnico de Construções Prediais e de graduação superior de Controle Tecnológico de Obras do então Centro Federal de Educação Tecnológica de Mato Grosso CEFETMT, que, além de alunos/as e professores/as incorporarem suas crenças pessoais a respeito do que é ser homem e mulher, os estudos de gênero relacionados à tecnologia apontam para a massiva masculinização de cursos como as engenharias. Ao ser questionada sobre quem eram os/as professores/as do C.V.E. em 1959, Adelina Maioli lembra que a área técnica era toda ministrada por professores, recordando seus nomes e área em que atuavam:

[...] o professor, ele era doutor, diretor doutor Amyntas de Assis Lage, que veio de uma estação de Minas Gerais da Embrapa. Ele veio pra cá porque era conhecido na parte de vinhos. O nosso professor chave era o doutor Pimentel, ali de Flores da Cunha. O professor Pimentel era

\footnotetext{
${ }^{20}$ Os professores eram Amyntas de Assis Lage, Antônio Ernesto Pasquali, Carlos Alberto Burnett, Emyr Farina, Fayez Rosek, Fernando Fasolo, Haimo Harmuth Fensterseifer, Henri Pierre Raffur, José Alcido Kolling, Loreno José Dal Sasso, Onofre de Oliveira Pimentel, Ormuz Freitas Rivaldo, Osvaldo Rodrigues Camargo, Paolo Fenocchio, Pedro Paulo Zanatta e Raymundo Luiz Marinho Carvalho.
} 
ótimo, maravilhoso. De enologia tinha um italiano, o Fenochio e tinha o pessoal daqui, da matemática, você sabe da química, era daqui era o Fernando (MAIOLI, 2013).

Essa homogeneização masculina, não só de corpo mas também de discurso, torna-se evidente com a ajuda da entrevista, sendo muitas vezes respaldada pelos próprios documentos oficiais das Instituições de Ensino, como é o caso do Regulamento da Escola de Viticultura e Enologia, no qual consta, no Capítulo VI, destinado ao ensino feminino, que, ao mesmo tempo em que era permitido o ingresso de mulheres e o ensino designava-se misto, não lhes era garantido o internato, bem como os programas e as práticas, que eram diferenciados. Sendo assim, o ingresso tornava-se um direito igual para homens e mulheres; entretanto, quando se tratava da permanência, o sexo masculino era privilegiado, pois ainda não se tinha alojamento que contemplasse o número cada vez mais crescente de meninas nos cursos da Instituição. A escola reforçava, a partir de seu próprio regulamento, a diferença entre a formação de homens e mulheres, como se percebe na transcrição a seguir:

\section{Capítulo VI}

Do Ensino Feminino

Art. $42 \mathrm{O}$ direito de ingresso nos cursos da Escola é igual para homens e mulheres, sendo facultada a coeducação.

Parágrafo único. Enquanto não houver instalações apropriadas e número suficiente de matrículas que justifiquem a manutenção do internato feminino, os alunos dêsse sexo só poderão ser matriculados em regime de externato ou semi-internato.

Art. $43 \mathrm{Na}$ execução dos programas e das práticas educativas para os alunos do sexo feminino levar-se-ão em conta as características do sexo não lhes sendo permitidos trabalhos inadequados. (BRASIL, 2013).

Essa naturalização dos gêneros está presente também na fala de Adelina, no momento em que a memória faz emergir a lembrança das aulas práticas, mencionando que "o doutor Amyntas achava que eu não precisava pegar na enxada, nada dessas coisas pesadas" (MAIOLI, 2013), mesmo ela tendo todos os materiais para as aulas práticas, desde as botas até as tesouras de podar, compradas pelo pai. Quando foi aprovada para cursar o Técnico em Viticultura e Enologia, com dezessete anos, Adelina não o viu como um curso "de homem", mas encarou "como um desafio, porque eu sempre gostei de desafios e meu pai também me deu muita força, pois ele gostava da área" (2013).

Das memórias de Adelina nos é apresentada mais uma importante narrativa. Da sua caixa ela retira dois canivetes de poda ${ }^{21}$ e enxertia, sendo que um deles foi presente de seu pai quando ela ingressou no curso, em 1959. A narrativa ganha mais emoção e [per]corre a memória da pesquisada com a lembrança do pai, desde o canivete de poda e enxertia até os livros importados da área da Viticultura e Enologia comprados por ele.

Adelina revela que o pai atuava no laboratório de enologia de Bento Gonçalves e nutria um interesse especial pela área. Decorre daí, talvez, o desejo de que sua filha também atuasse na área da enologia, seguindo as suas anotações que, conforme Adelina, eram realizadas em muitos cadernos, pois naquele período o processo empírico se sobressaía na

\footnotetext{
${ }^{21}$ A poda da videira é uma prática realizada no curso Técnico em Viticultura e Enologia e visa regularizar o crescimento vegetativo e reprodutivo da planta, assegurando a sua perenidade e a produção de uvas de qualidade. Consiste no corte total ou parcial de determinados órgãos da planta. Para realizar a poda da videira são utilizadas tesoura de poda manual, serrote de podar e, mais recentemente, tesoura de poda elétrica. Os canivetes são mais utilizados para a realização da enxertia da videira.
} 
produção de vinhos. Alguns desses cadernos com as anotações da época estão com Adriana, filha de Adelina, que os guarda como recordação do avô, um homem que, no final da década de 1950 incentivou a sua filha a adentrar num espaço que se tornaria posteriormente um reduto masculino, possibilitando, desde este período, que fosse possível problematizar as relações de gênero no ensino técnico.

De acordo com a sua narrativa, depois de concluir o curso técnico, ela fez concurso para o Estado e foi aprovada, passando a atuar a partir de 1963 no mesmo laboratório de enologia em que o pai tinha trabalhado. No final da década de 1970, Adelina trocou o laboratório de enologia pela secretaria da saúde e, apesar de ter sido aprovada em concurso que havia realizado para a Embrapa neste período, optou por não assumir, e deixa presente em sua fala o arrependimento por não ter atuado por mais tempo na área da enologia:

[...] a gente fazia tudo manual e era muito interessante. Depois eu saí. Troquei de secretaria e fui fazer um estágio quando eu fui pra saúde, mas tudo em função da família. Eu tinha criança pequena e me ofereceram uma proposta boa na saúde, que estava em falta de técnico de laboratório. Então fiz um cursinho em Porto Alegre e troquei de secretaria, mas me arrependi. Até por sinal eu fiz um concurso pra Embrapa, passei, naquela ocasião eu tinha ficado em segundo lugar e não assumi, eu tava grávida da minha última filha e aí veio uma série de problemas e eu não pude assumir, é uma coisa que eu sempre senti mesmo, eu teria continuado (MAIOLI, 2013).

O final de 1950 e a década de 1960 estavam marcados pela naturalização da representação feminina e a região da serra gaúcha se revestia da "fabricação de santas-mãezinhas", para usar o termo de Mary Del Priore (2009), em função da influência marcante da Igreja nesta região de imigração italiana. Diante deste cenário e mesmo tendo recebido o apoio do pai para que concluísse seus estudos, a Técnica em Viticultura e Enologia Adelina se restringe a cuidar de sua família, sendo monopolizada pelo trabalho doméstico, corroborando com o que Perrot (2005) menciona sobre a condição da mulher de que "fazer carreira é uma noção pouco feminina e que implica, em todo caso, em uma renúncia, sobretudo do casamento" (p. 255).

O olhar atento de professores e colegas, o lenço na cabeça e a saia comprida característicos da época, mesmo em dia de atividade prática possivelmente representam a concepção de uma mulher naturalmente meiga, sensível e frágil. Será que ela consegue? Os corpos masculinos se curvam para acompanhar de perto a menina Adelina que realiza uma atividade prática de poda, conforme seu relato ao nos apresentar esta fotografia, num provável indicativo de representação do sentido de proteção masculina que impera quando as relações de gênero são abordadas a partir dos binarismos emoção/razão, força/fragilidade, dominação/passividade, dentre tantos outros.

Diante da naturalização de que o homem é aquele que tem facilidade para as atividades de cunho técnico, enquanto a mulher é apenas dedicada, emerge a possibilidade de encontrar, na figura 3, o foco central da imagem não na aluna que realiza a atividade - e que inclusive é de difícil identificação por causa do lenço - mas nos três homens que olham diretamente para a ação realizada por ela. Arriscamos observar que possivelmente essa ação de manter o olhar na ação da única mulher tensiona o momento de aprendizagem. 
Figura 3: A aluna Adelina Maria Mussoi realizando atividade prática de poda de cítricos, em 1961.

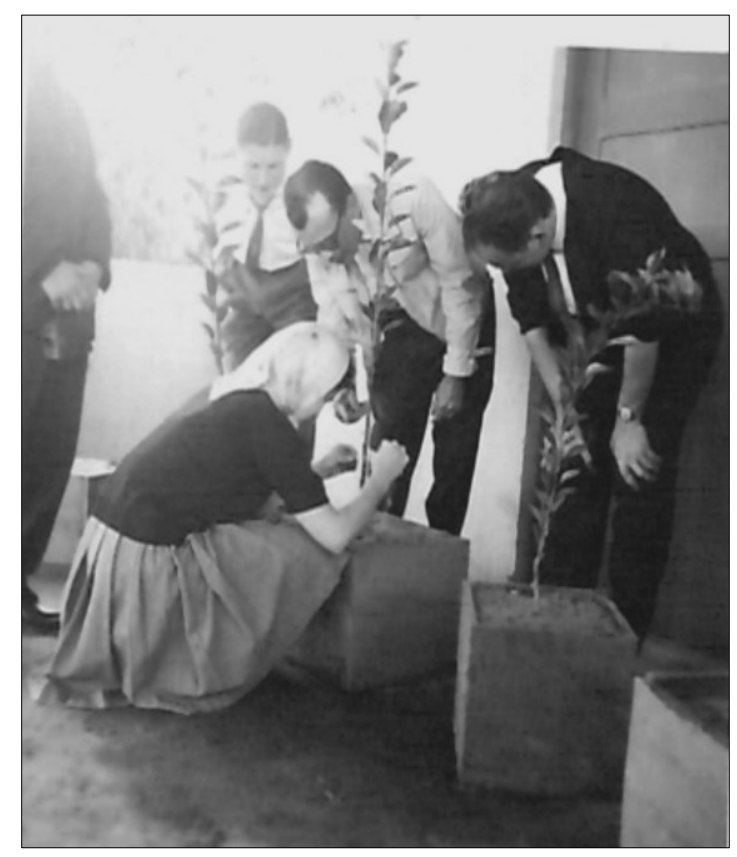

Fonte: Acervo pessoal de Adelina Maria Mussoi Maioli, 2013.

O nosso encontro com Adelina foi marcado pelo prazer, pela confiança e pelo desejo em contar uma história que muitos sabiam, mas que poucos valorizaram. Desde 1959 [até hoje!], muitas das Técnicas em Viticultura e Enologia formadas pela Instituição são contratadas como auxiliares das atividades laboratoriais, sendo responsáveis pela organização e limpeza das vidrarias, enquanto os Técnicos são os que aprofundam seus saberes na manipulação de reagentes e no controle da qualidade.

Atualmente, o campus Bento Gonçalves do Instituto Federal de Educação, Ciência e Tecnologia conta com um total de 118 docentes, dos quais 55 são mulheres. Quanto ao número de matrículas, o curso técnico em Viticultura e Enologia registrou no ano de 2019 o total de 83 estudantes, dos quais 50 são meninas, conforme dados obtidos junto à Coordenadoria de Registros Acadêmicos do campus Bento Gonçalves. Com o crescente aumento no número de meninas matriculadas, instalou-se na instituição desde 2012 uma política de auxílio moradia às alunas que necessitavam pagar aluguel no município, como forma de incentivar sua permanência e êxito, já que os meninos, naquela época, usufruíam de alojamento estudantil localizado dentro do campus. Contudo, urge ainda a necessidade de políticas públicas que possibilitem a permanência dessas estudantes no ensino técnico, dandolhes igualdade de condições de ingresso, permanência e êxito.

Entretanto, por mais que a instituição tente estabelecer a equidade de gênero, proposta na luta dos movimentos feministas e teorizada em várias autoras a partir do conceito de gênero (SCOTT, 2005), o sexismo se constitui como elemento significativo e muito presente em situações e práticas nos cursos técnicos em que os meninos são considerados os "mais capacitados" ou os "adequados" para participarem. A constatação do benefício do alojamento, o cuidado e manejo com os animais, a existência de vestiário masculino para troca de roupa antes e após a aula prática, são fatos determinantes para essa observação.

$\mathrm{O}$ encontro com a primeira mulher que estudou na então Escola de Viticultura e Enologia, entrevistá-la, analisar documentos e fotografias compuseram um recorte que nos desafiou a ampliar e aprofundar o caminho investigativo. As fotografias [res]guardam a memória e a história da instituição e das pessoas que constituem esse ambiente de ensino. Detalhes que revelam relações de gênero que produzem compreensões dualistas naturalizadas 
como coisas de mulheres e coisas de homens. Enxergar esses modos de naturalizar e, de certa forma, não reproduzi-los, pode auxiliar a desconstruir, por meio do debate, o modo como essa discussão ocorre num curso técnico.

A despedida após a entrevista com a Adelina encerrou uma etapa da curiosidade epistemológica sobre a história de um curso técnico povoado por homens e ousado por uma mulher. Ao cerrar a porta do seu apartamento, que foi aberto tão gentilmente, não fazemos ideia do que tudo passou pela cabeça da nossa entrevistada, mas na nossa ficou entreaberta a problematização das relações de gênero no ensino técnico. "Descortinar" essa presença feminina na primeira turma do curso técnico em Viticultura e Enologia possibilitou olharmos com outra perspectiva para a Instituição e para as relações de gênero entrelaçadas com o ensino técnico. O fato de Adelina ter sido integrante da primeira turma da Escola de Viticultura e Enologia é um indício de que as mudanças já apontavam para o debate e a problematização das relações de gênero, possibilitando que as mulheres escrevessem, cotidianamente, as suas histórias neste espaço educativo.

\section{Referências}

ANDERLE, Marilei. Histórico da Escola Federal Presidente Juscelino Kubitschek. Bento Gonçalves: UCS, mimeografado, 1998.

BANDEIRA, Lourdes. A contribuição da crítica feminista à ciência. Estudos Feministas, v. 16, n. 1, p. 207-228, 2008. https://doi.org/10.1590/s0104-026x2008000100020

BOHNSACK, Ralf. A interpretação de imagens e o Método Documentário. Sociologias, n. 18, p. 286-311, 2007. https://doi.org/10.1590/s1517-45222007000200013

BRASIL. Decreto $\mathrm{n}^{\circ}$ 7.566, de 23 de setembro de 1909. Cria nas capitais dos Estados as Escolas de Aprendizes e Artífices, para o ensino profissional primário e gratuito. Rio de Janeiro, setembro de 1909.

. Decreto-Lei n ${ }^{0}$ 9.613, de 20 de agosto de 1946. Dispõe sobre a Lei Orgânica do Ensino Agrícola. Diário Oficial da União. Rio de Janeiro, 22 de agosto de 1946.

. Decreto $\mathrm{n}^{\mathrm{o}}$ 538, de 23 de janeiro de 1962. Aprova o Regulamento da Escola de Viticultura e Enologia de Bento Gonçalves e dá outras providências. Diário Oficial da União. Brasília: Ministério de Estado dos Negócios da Agricultura, 1962.

. Decreto $\mathrm{n}^{\mathrm{o}}$ 53.558, de 13 de fevereiro de 1964. Altera a denominação de escolas de iniciação agrícola, agrícolas e agrotécnicas. Diário Oficial da União. Brasília: Ministério da Agricultura, 22 de fevereiro de 1964.

. Decreto no 60.731, de 19 de maio de 1967. Transfere para o Ministério da Educação e Cultura os órgãos de ensino do Ministério da Agricultura e dá outras providências. Diário Oficial da União. Brasília: Ministério da Agricultura, 22 de maio de 1967.

. Decreto ${ }^{0} 72.434$, de 9 de julho de 1973. Cria a Coordenação Nacional do Ensino Agrícola - COAGRI - no Ministério da Educação e Cultura, atribuindo-lhe autonomia administrativa e financeira e dá outras providências. Diário Oficial da União. Brasília: Ministério da Educação e Cultura, 10 de julho de 1973. 
Relatório Geral do Ministério da Educação e Cultura de 1977. Brasília: Ministério

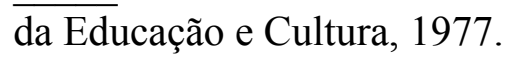

Diretrizes de Funcionamento de Escolas Agrotécnicas. Brasília: MEC/SENETE, 1990.

. Decreto 2.406 de 27 de novembro 1997. Regulamenta a Lei Federal no 8.948/94 (trata de Centros de Educação Tecnológica). Diário Oficial da União. Brasília: Ministério da Educação e Cultura, 27 de novembro de 1997.

. Lei 11.892/2008, de 29 de dezembro de 2008. Institui a Rede Federal de Educação Profissional, Científica e Tecnológica, cria os Institutos Federais de Educação, Ciência e Tecnologia, e dá outras providências. Diário Oficial da União. Brasília: Ministério da Educação e Cultura, 29 de dezembro de 2008.

CARDOSO, Sergio Ricardo Pereira. Os primórdios da educação profissional em Viticultura e Enologia na região da Serra Gaúcha. \# Tear: Revista de Educação, Ciência e Tecnologia, v. 1, n. 2, 2012. https://doi.org/10.35819/tear.v1.n2.a1756

COOPERATIVA Escolar e de Trabalho Dos Alunos do Colégio de Viticultura e Enologia Ltda. Livro Ata no 1, p. 1-100, 1979.

DEL PRIORI, Mary. Ao sul do corpo: condição feminina, maternidade e mentalidades no Brasil Colônia. São Paulo: Editora UNESP, 2009.

FIGUEIREDO, Luiz Carlos de. O gênero na educação tecnológica: uma análise de relações de gênero na socialização de conhecimentos da Área de Construção Civil do Centro Federal de Educação Tecnológica de Mato Grosso. 2008, 146 f. Dissertação (Mestrado em Política Científica e Tecnológica) - Universidade Estadual de Campinas, São Paulo, 2008.

HALBWACHS, Maurice. A memória coletiva. Trad. de Beatriz Sidou. São Paulo: Centauro, 2006.

JALFIM, Anete. Elementos para o estudo da agroindústria vinícola: uma abordagem da Cooperativa Vinícola Aurora. Ensaios FEE, v. 14, n. 2, p. 689-708, 1993.

KOLLER, Claudio Adalberto. A perspectiva histórica da criação da Escola Agrotécnica Federal de Rio do Sul e a sua relação com o modelo agrícola convencional. 2003, $182 \mathrm{f}$. Dissertação (Mestrado em Agroecossistemas) - Universidade Federal de Santa Catarina, Santa Catarina, 2003.

LUPORINI, Teresa Jussara. Memória e fontes iconográficas: os desafios para a pesquisa em história da educação. Revista Diálogo Educacional, v. 5, n. 14, p. 1-29, 2005. https://doi.org/10.7213/rde.v5i14.7379

MACHADO, Lucília R. de Sousa. Educação e divisão social do trabalho: contribuição para o estudo do ensino técnico industrial brasileiro. São Paulo: Autores Associados; Cortez, 1982.

MAIOLI, Adelina Maria Mussoi. Entrevista. Maio de 2013. Entrevista oral concedida a Edson Carpes Camargo. 
MARQUES, Oscilene Simões. Análise Curricular da Implementação da Reforma da Educação Profissional na Escola Agrotécnica Federal de Colatina/ES. 2005, 168 f. Dissertação (Mestrado em Educação Agrícola) - Universidade Federal Rural do Rio de Janeiro, Rio de Janeiro, 2005.

PERROT, Michelle. As mulheres ou os silêncios da história. Tradução de Viviane Ribeiro. Bauru: EDUSC, 2005.

SILVA, Henrique M. Alguns apontamentos sobre o uso de fotografias em pesquisas históricas. Revista de História Regional, v. 5, n. 2, 2000.

SILVA, Lidiane Rodrigues Campêlo da et al. Pesquisa documental: alternativa investigativa na formação docente. In: IX Congresso Nacional de Educação-EDUCERE-III Encontro Sul Brasileiro de Psicopedagogia, Paraná. 2009. p. 4554-4566.

SOUZA, Flávio Abreu de. Mudanças promovidas no setor vitivinícola do Rio Grande do Sul pela inserção de profissionais especializados nas áreas de viticultura e enologia. 2005, 159 f. Dissertação (Mestrado em Ciências) - Universidade Federal Rural do Rio de Janeiro, Rio de Janeiro, 2005.

TAVARES, Carlos Alberto. A formação do técnico em agropecuária no sistema escolafazenda. Anais da Academia Pernambucana de Ciência Agronômica, v. 4, p. 314-339, 2007. 